\title{
Prevalence of Abnormalities of Glucose Metabolism in Patients With Polycystic Ovary Syndrome
}

\begin{abstract}
Patients with polycystic ovary syndrome (PCOS) present a higher risk for abnormalities of glucose metabolism (AGM). For to study this in our population, we submitted 85 patients, with body mass index (BMI) of $28.5 \pm 6.6$ $\mathrm{kg} / \mathrm{m}^{2}$ and aged $25.5 \pm 5.4$ years old, to an oral glucose tolerance test (OGTT), and assessed the impact of BMI on the prevalence of impaired glucose tolerance (IGT) and of diabetes mellitus (DM). The states of glucose tolerance were classified considering fasting plasma glucose (FPG) according to the American Diabetes Association (ADA) criterion and plasma glucose at 120 minutes according to the Word Health Organization (WHO) criterion. According to the ADA criteria, $83.5 \%$ classified as normal and $16.5 \%$ as with AGM, with $15.3 \%$ presenting impaired fasting glucose and $1.2 \% \mathrm{DM}$, while according to the WHO criteria, $68.2 \%$ were classified as normal and $31.8 \%$ as with AGM, with $27.0 \%$ of them presenting IGT and 4.8\% DM. Seventy-three percent of PCOS patients with IGT by WHO criterion had normal FPG by ADA criterion. The prevalence of AGM for both criteria increased with the body mass index. In conclusion, we found a higher prevalence of AGM in PCOS patients than that found in the general population, being the highest in obese patients. Glycemia at 120 minutes on the OGTT identified more patients with AGM than fasting glycemia. We recommended that the assessment of AGM must be done by the OGTT in all patients with PCOS. (Arq Bras Endocrinol Metab 2007;51/4:601-605)
\end{abstract}

Keywords: Polycystic ovary syndrome; Impaired glucose tolerance; Diabetes mellitus

\section{RESUMO}

Prevalência de Anormalidades do Metabolismo de Glicose em Pacientes com a Síndrome dos Ovários Policísticos.

Pacientes com a síndrome dos ovários policísticos (SOP) têm um risco maior para desenvolver anormalidades do metabolismo da glicose (AMG). Para avaliarmos a prevalência dessas anormalidades na nossa população, submetemos 85 pacientes, com índice de massa corporal (IMC) de $28,5 \pm 6,6 \mathrm{~kg} / \mathrm{m}^{2}$ e média etária de 25,5 $\pm 5,4$ anos, a teste de tolerância oral à glicose (TTOG). Os estados de tolerância à glicose foram classificados considerando a glicemia de jejum (GJ; American Diabetes Association - ADA) e glicemia aos 120 minutos (G120; Organização Mundial de Saúde - OMS). De acordo com a ADA, 83,5\% das pacientes foram normais e $16,5 \%$ com AMG, com 15,3\% apresentando glicemia de jejum imprópria e 1,2\% diabetes mellitus (DM). De acordo com a OMS, $68,2 \%$ foram normais e 31,8\% com AMG, com $27,0 \%$ apresentando intolerância à glicose (IG) e $4,8 \%$ DM. Observamos que $73 \%$ das pacientes com IG pelos critérios da OMS apresentavam GJ normal pelos critérios da ADA. A prevalência de AMG para ambos os critérios foi maior entre as pacientes com IMC mais elevado. Conclusão: encontramos maior prevalência de AMG nas pacientes com a SOP do que na população geral, sendo mais elevada entre as pacientes obesas. Além disso, a G120 no TTOG identificou maior número de pacientes com AMG do que a GJ. Assim, recomendamos avaliação de AMG através do TTOG para todas as pacientes portadoras da SOP. (Arq Bras Endocrinol Metab 2007;51/4:601-605)

Descritores: Síndrome dos ovários policísticos; Intolerância à glicose; Diabetes mellitus artigo original

\author{
CRISTIANo R.G. BARCELLOS \\ Michelle P. ROCHA \\ SYLVIA A.Y. HAYASHIDA \\ MÁRCIA NERY \\ José A.M. MARCONDES
}

Endocrine Unit (CRGB, MPR, MN \& JAMM) and Gynecologial Clinic (SAYH), Hospital das Clínicas da Faculdade de Medicina da Universidade de São Paulo, SP.

Recebido em 19/09/06 Revisado em 02/01/07 Aceito em 17/01/07 
P OLYCYSTIC OVARY SYNDROME (PCOS) is a heterogeneous disorder, characterized by chronic anovulation and hyperandrogenism, affecting between 6 to $10 \%$ of women of reproductive age (1). It is currently considered a complex metabolic disorder and a risk factor for diabetes mellitus (DM), cardiovascular disease and endometrial cancer (2-4). It is believed that insulin resistance might be a link between carbohydrate intolerance and the increase in cardiovascular risk and PCOS (5).

In 1992, Dalghren et al. (6) reported that the prevalence of DM in menopause women with PCOS was 15\%. Recent reports on North American Caucasian and African-American origin patients established the prevalence of IGT as being 31.1-35\% and DM as $7.5-10 \%$ in PCOS patients $(2,7,8)$.

The aim of this study is to assess the prevalence of abnormalities of glucose metabolism (AGM) in PCOS patients from the city of São Paulo and to evaluate the usefulness of the recommendation of the American Diabetes Association (9) versus the Word Health Organization (WHO) (10) on diagnosis of carbohydrate tolerance states.

\section{PATIENTS AND METHODS}

All patients registered as having PCOS at the Outpatient Hirsutism Clinic of the Endocrine Unit of Hospital das Clínicas de São Paulo from 2000 to 2004 were studied retrospectively. The patients were referred to the clinic for hirsutism evaluation. The PCOS diagnosis was based on the presence of hirsutism and menstrual dysfunction, after exclusion of Cushing's syndrome, late-onset 21-hydroxylase deficiencies, thyroid dysfunction, hyperprolactinemia, or androgen-secreting tumor by appropriated tests. None of the subjects had other diseases or were taking any medication for at least 6 months prior to the study.

Oral glucose tolerance test (OGTT) was performed between 7:30 and 8:30 A.M. After an overnight fast, blood samples were obtained through an IV catheter placed in the forearm for the determination of fasting blood glucose. A $75 \mathrm{~g}$ of glucose load was given, and blood collected after 30, 60, 90 and 120 minutes thereafter, for determination of glucose.

Plasma glucose concentration was determined by the glucose oxidase method using a glucose analyzer (Beckman Instruments, Palo Alto, CA).

The states of glucose tolerance were classified considering fasting plasma glucose (FPG) according to the ADA criteria from 2003 (impaired fasting plasma glucose - IFG: plasma glucose $>99 \mathrm{mg} / \mathrm{dL}$ and $<126 \mathrm{mg} / \mathrm{dL}$; DM: plasma glucose $\geq 126 \mathrm{mg} / \mathrm{dL}$ ) (9) and plasma glucose at 120 minutes according to the WHO criterion from 1999 (IGT: plasma glucose $\geq 140 \mathrm{mg} / \mathrm{dL}$ and $<200 \mathrm{mg} / \mathrm{dL}$; DM: plasma glucose $\geq 200 \mathrm{mg} / \mathrm{dL})(10)$.

\section{Statistical analyses}

Unpaired and nonparametric Student's t-test was used to compare plasma glucose between the groups. Results are expressed as the means \pm standard deviation (SD). A twotailed p-value less than 0.05 was considered as statistically significant for all analyses.

\section{RESULTS}

Eighty-five patients with body mass index (BMI) of $28.5 \pm 6.6 \mathrm{~kg} / \mathrm{m}^{2}$ and aged $25.5 \pm 5.4$ years old, met the adopted criteria of PCOS. All of them presented menstrual abnormalities. According to the BMI, $34.1 \%$ were normal, $31.8 \%$ were overweight and $34.1 \%$ of them were obese, while $7 \%$ were morbidly obese.

Regarding the prevalence of AGM, according to the WHO criteria, $68.2 \%$ were classified as normal and $31.8 \%$ as with AGM, been $27.0 \%$ with IGT and $4.8 \%$ with DM. According to the ADA criteria, $83.5 \%$ classified as normal and $16.5 \%$ as with AGM, with $15.3 \%$ presenting IFG and $1.2 \% \mathrm{DM}$.

Seventy-three percent of the PCOS patients with IGT by WHO criterion had normal fasting glucose levels by ADA criterion. Of the four patients with diabetes by the WHO criterion, one had fasting plasma glucose $(\mathrm{FPG})>126 \mathrm{mg} / \mathrm{dL}$, one had FPG between 99 and $126 \mathrm{mg} / \mathrm{dL}$ and two had FPG < $100 \mathrm{mg} / \mathrm{dL}$.

According to the BMI, the FPG was $86.4 \pm 7.7$ $\mathrm{mg} / \mathrm{dL}, 90.9 \pm 10.6 \mathrm{mg} / \mathrm{dL}$ and $95.3 \pm 11.9 \mathrm{mg} / \mathrm{dL}$ in normal, overweight and obese patients, respectively, with a significant difference between normal and overweight $(\mathrm{p}=0.04)$ and between normal and obese $(\mathrm{p} \leq$ 0.001 ) patients. The plasma glucose at 120 minutes of the GTTO was $115.6 \pm 46.2 \mathrm{mg} / \mathrm{dL}, 115.7 \pm 33.4$ $\mathrm{mg} / \mathrm{dL}$ and $133.3 \pm 58.6 \mathrm{mg} / \mathrm{dL}$ in normal, overweight and obese patients, respectively, without significant differences among the groups. The prevalence of AGM by the BMI is shown in figure 1 . There was an increased prevalence of AGM according to the increase in BMI. The plasma glucose at 120 minutes of OGTT identified AGM 6.76, 2.16 and 1.27 times more than FPG in the normal, overweight and obese patients, respectively.

According to the age range, the glycemia at 120 minutes of the OGTT was $110.3 \pm 22.2 \mathrm{mg} / \mathrm{dL}$ for those $<20 \mathrm{yr}(\mathrm{n}=12), 121.2 \pm 56.8 \mathrm{mg} / \mathrm{dL}$ for 20 to $24 \mathrm{yr}(\mathrm{n}=25), 118.9 \pm 35.2 \mathrm{mg} / \mathrm{dL}$ for 25 to $29 \mathrm{yr}(\mathrm{n}=$ $33), 132.6 \pm 83.2 \mathrm{mg} / \mathrm{dL}$ for 30 to $34 \mathrm{yr}(\mathrm{n}=9)$ and $145.2 \pm 36.4 \mathrm{mg} / \mathrm{dL}$ to $\geq 35 \mathrm{yr}(\mathrm{n}=6)$, with significant difference only between the youngest and the oldest groups $(p=0.03)$. As can be seen in figure 2 , there was a higher prevalence of AGM in the age group > $35 \mathrm{yr}$. 


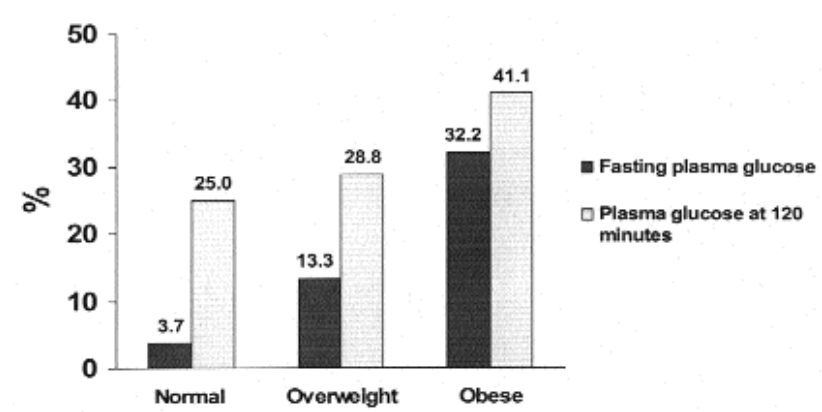

Figure 1. Prevalence of abnormalities of glucose metabolism according to the ADA criteria (fasting plasma glucose) and the WHO criteria (plasma glucose at 120 minutes of the oral glucose tolerance test) in patients with polycystic ovary syndrome according to body mass index.

\section{DISCUSSION}

In this study, the prevalence of AGM in patients with PCOS was $31.8 \%$ according to the $\mathrm{WHO}$ criteria, and $16.5 \%$ according to the ADA criteria. This prevalence was well above those reported among normal Brazilian women of similar ages. In a two-stage, multicenter, cross-sectional survey in a random sample of 21,847 individuals aged 30-69 yr from nine large cities, according to WHO recommendations, the overall rates were 7.6 and $7.8 \%$ for diabetes and IGT, respectively, with similar rates being found among whites $(7.8 \%)$ and nonwhites $(7.3 \%)$ (11). For the aged 30-39 yr, the prevalences were 2.7 and $5.9 \%$ for diabetes and IGT, respectively. In another study, in a two-stage, cross-sectional home survey in the city of Ribeirão Preto, SP, with an urban random sample of 1,473 individuals aged 30-69 years, the prevalences of IGT and DM based on WHO criteria were 12.1 and $7.7 \%$, respectively (12). Differences in the diabetes rates for whites (11.6\%) and nonwhites (13.3\%) were not significant, while IGT was more prevalent among whites.

The prevalence rates of AGM in PCOS change according to the population study and the criterion used for the diagnosis of glucose intolerance. As one of the aims of this study was to compare the prevalence rate of AGM according to the $\mathrm{WHO}$ versus ADA criteria, we will discuss mainly the studies that also done this comparison. In the United States, according to the WHO criteria, the prevalence rates were $31.1 \%$ for impaired glucose tolerance and $1.5 \%$ for diabetes (2), while the ADA diagnostic criteria failed to detect a significant number of PCOS women with diabetes by post challenge glucose values $(3.2 \%$ for glucose intolerance and $4.7 \%$ for diabetes). Considering the WHO

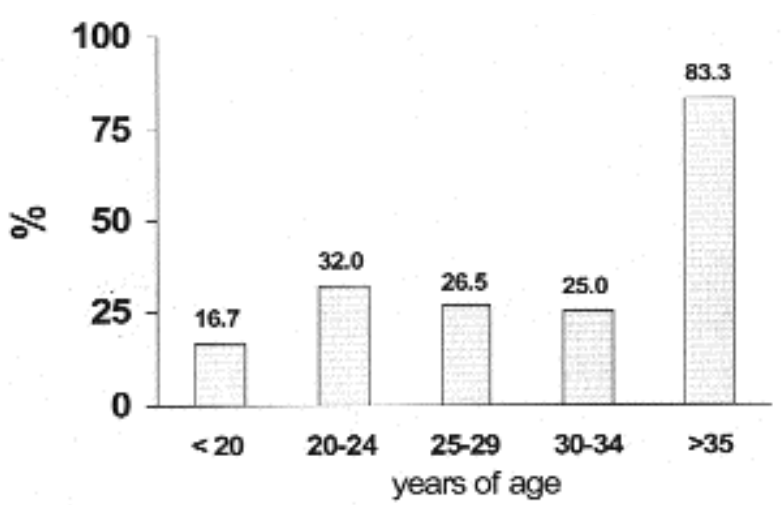

Figure 2. Prevalence of abnormalities of glucose metabolism (plasma glucose at 120 minutes on the oral glucose tolerance test) in patients with polycystic ovary syndrome according to age.

criterion, this prevalence was substantially higher than those found in a major-normal population-based study carried out in Second National Health and Nutrition Study with patients of similar ages (IGT: 7.8\%; DM: $1.0 \%)(13)$ and also above those reported among United States normal Hispanic and African-American women of similar ages (14). These prevalence rates of IGT and DM did not differ in two groups of PCOS patients studied, one from an urban, ethnically-mixed group and one from a rural, ethnically-homogeneous group (2). A report by Ehrmann et al. (8) found similar prevalence rates in an ethnically-mixed PCOS population from the Chicago area, which could imply that PCOS is a more important risk factor for glucose intolerance in young patients than age and ethnicity $(2,8)$.

A higher prevalence of glucose intolerance in PCOS patients according to the WHO criteria was also seen in a group of 79 patients from Thailand (IGT: 20.3\%; DM: 9.5\%) (15). However, when the fasting blood glucose was assessed according to the ADA criteria, the prevalence of IFG decreased to $3.8 \%$ and the prevalence of DM decreased to $6.3 \%$.

Fasting glucose levels were poor predictors of AGM in this study, as well as in the study of Legro et al. in the United States (2) and in that of Weerakiet et al. in Thailand (15), since the ADA criteria failed to detect a significant number of PCOS patients with AGM. Considering the ADA criteria, $16.5 \%$ of our patients had AGM. On the other hand, considering the post challenge glucose value, the prevalence of these disturbances abnormalities increased to $31.84 \%$. This means that, if we considered only the fasting plasma glucose value as a diagnostic criterion for AGM, one in two patients according to the ADA criteria would be missed. Similarly, one patient with diabetes according to the post-challenge glucose value 
would be considered as having normal glucose tolerance by the fasting glucose value, according to the ADA criteria. This is especially true for patients with normal BMI, as glucose at 120 minutes of the OGTT detects 6.76 times more cases of AGM than fasting plasma glucose, and while in obese patients glucose at 120 minutes of the OGTT detects only 1.27 more cases of AGM than FPG.

In this study, only $34.1 \%$ of the patients were obese, with $7 \%$ of them being morbidly obese. In the study by Legro et al., $73 \%$ had a BMI $\geq 27 \mathrm{~kg} / \mathrm{m}^{2}(2)$, while in Thailand, only $26.6 \%$ of the study subjects were obese, in the same age range (15). As we observed, for FPG, a higher prevalence of AGM was attained using the WHO criteria. According to this criterion, the BMI impact on the prevalence of AGM was observed only for a BMI $\geq 30 \mathrm{~kg} / \mathrm{m}^{2}$, while according to the ADA criteria, there was a progressive impact of $\mathrm{BMI}$ on the prevalence rates of glucose intolerance, increasing from $3.7 \%$ in the range of $<25 \mathrm{~kg} / \mathrm{m}^{2}$ to $32.2 \%$ in the range of $\geq 30 \mathrm{~kg} / \mathrm{m}^{2}$. It is interesting to note that, although the prevalence of obesity in our population was greater than that observed in the study from Thailand $(34.1 \%$ vs. $26.6 \%)$, the prevalence of the AGM, mainly which of diabetes, for both criteria, was much higher in Thailand. This way, risk factors others than BMI must be considered, as the genetic background, a positive family history of type 2 diabetes and the degree of hyperandrogenism.

We observed that the prevalence of AGM, by the WHO criteria, occurred before the one that is commonly seen by age in normal women. Similar results were observed by Legro et al., by the WHO criteria, although in a more advanced age range (> $40 \mathrm{yr}$ ). In the study of Weerakiet et al., from Thailand (15), the smaller prevalence of AGM according to WHO criteria was seen for patients less than 20 years of age $(2.5 \%)$ and increased up to $11.4 \%$ in the other age ranges, without a clear influence for each age range. An important bias regarding these data is the lower number of patients in more advanced age range. Nevertheless, in the present study, obesity was not more prevalent in patients $\geq 35 \mathrm{yr}$ than those in the other age ranges. It's possible that this increase in prevalence in the fourth decade of life can reflect the natural history of AGM in patients with PCOS. In fact, AGM, as categorized by WHO criteria, tends to worsen over time in women with PCOS, with a non-significant nearly 2 -fold increase in the rates of conversion for subjects with PCOS and baseline normal glucose tolerance, without a concomitant change in BMI (16).
In conclusion, the risk of AGM among PCOS patients seems to be at least 2-fold higher, increasing with the BMI, and occurring at an earlier age than in the normal population. Glycemia at 120 minutes on the OGTT (the WHO criteria) identified more patients than fasting glycemia (ADA criteria), mainly in patients with normal BMI. We recommended that the assessment of AGM must be done in all patients with PCOS, been in those patients with normal BMI by the OGTT, and repeated over time, mainly after the $5^{\text {th }}$ decade of life.

\section{ACKNOWLEDGEMENTS}

We thank Ms. Sonia Strong for the English review.

\section{REFERENCES}

1. Knochenhauser ES, Key TJ, Kahsar-Miller M, Waggoner W, Boots LR, Azziz R. Prevalence of the polycystic ovary syndrome in unselected black and white women of southeastern United States: a prospective study. J Clin Endocrinol Metab 1998;83:3078-82.

2. Legro RS, Kunselman AR, Dodson WC, Dunaif A. Prevalence and predictors of risk for type 2 diabetes mellitus and impaired glucose tolerance in polycystic ovary syndrome: a prospective, controlled study in 254 affected women. J Clin Endocrinol Metab 1999;84:165-9.

3. Legro RS. Polycystic ovary syndrome and cardiovascular disease: a premature association? Endoc Rev 2003;24:302-12.

4. Rose PG. Endometrial carcinoma. N Engl J Med 1996;335:640-9.

5. Dunaif A. Insulin resistance and the polycystic ovary syndrome: mechanism and implications for pathogenesis. Endoc Rev 1997:18:774-800.

6. Dahlgren E, Johansson S, Lindstedt G, Knutsson F, Oden A, Lundberg PA, et al. Women with polycystic ovary syndrome wedge resected in 1956 to 1965: a long-term follow-up focusing on natural history and circulating hormones. Fertil Steril 1992;57:505-13.

7. Legro RS, Kunselman AR, Dodson WC, Dunaif A. Prevalence and predictors of risk for type 2 diabetes mellitus and impaired glucose tolerance in polycystic ovary syndrome: a prospective, controlled study in 254 affected women. J Clin Endocrinol Metab 1999;84:165-9.

8. Erhmann DA, Barnes RB, Rosenfield RL, Cavaghan MK, Imperial J. Prevalence of impaired glucose tolerance and diabetes in women with polycystic ovary syndrome. Diabetes Care 1999;22:141-6.

9. Genuth S, Alberti KG, Bennett P, Buse J, Defronzo R, Zimmet $P$, et al. The Expert Committee on the Diagnosis and Classification of Diabetes Mellitus: follow-up report on the diagnosis of diabetes mellitus. Diabetes Care 2003: 26:3160-7.

10. World Health Organization. Definition, diagnosis and classification of diabetes mellitus and its complications: report of a WHO consultation. Part I. Diagnosis and classification of diabetes mellitus. WHO: Geneva, 1999.

11. Malerbi DA, Franco LJ. Multicenter study of the prevalence of diabetes mellitus and impaired glucose tolerance in the urban Brazilian population aged 30-69 yr. The Brazilian Cooperative Group on the Study of Diabetes Prevalence. Diabetes Care 1992;15(11):1509-16. 
12. Torquato MT, Montenegro Junior RM, Viana LA, de Souza RA, Lanna CM, Foss MC, et al. Prevalence of diabetes mellitus and impaired glucose tolerance in the urban population aged 30-69 years in Ribeirão Preto (São Paulo), Brazil. São Paulo Med J 2003;121:224-30.

13. Harris MI, Hadden WC, Knowler WC, Bennett PH. Prevalence of diabetes and impaired glucose tolerance and plasma glucose levels in U.S. population aged 20-74 yr. Diabetes 1987; $36: 523-34$

14. Harris MI, Flegal KM, Cowie CC, Eberhardt MS, Goldstein DE, Byrd-Holt DD, et al. Prevalence of diabetes, impaired fasting glucose, and impaired glucose tolerance in U.S. adults. Diabetes Care 1998;21:518-24.

15. Weerakiet S, Srisombut C, Bunnag P, Sangtong S, Chuangsoongnoen N, Rojanasakul A. Prevalence of type 2 diabetes mellitus and impaired glucose tolerance in Asia women with polycystic ovary syndrome. Internat J Gynecol Obst 2001;75:177-84.
16. Legro RS, Gnatuk CL, Kunselman AR, Dunaif A. Changes in glucose tolerance over time in women with polycystic ovary syndrome: a controlled study. J Clin Endocrinol Metab 2005;90:3236-42.

Endereço para correspondência:

José Antonio Miguel Marcondes

Rua Baronesa de Itu 821, apto. 112

01231-001 São Paulo, SP

Fax: (1 1) 3159-0582

E-mail: marcondesmd@uol.com.br 